Document downloaded from:

http://hdl.handle.net/10251/66721

This paper must be cited as:

Martínez Las Heras, R.; Heredia Gutiérrez, AB.; Castelló Gómez, ML.; Andrés Grau, AM. (2014). Influence of drying method and extraction variables on the antioxidant properties of persimmon leaves. Food Bioscience. 6:1-8. doi:10.1016/j.fbio.2014.01.002.

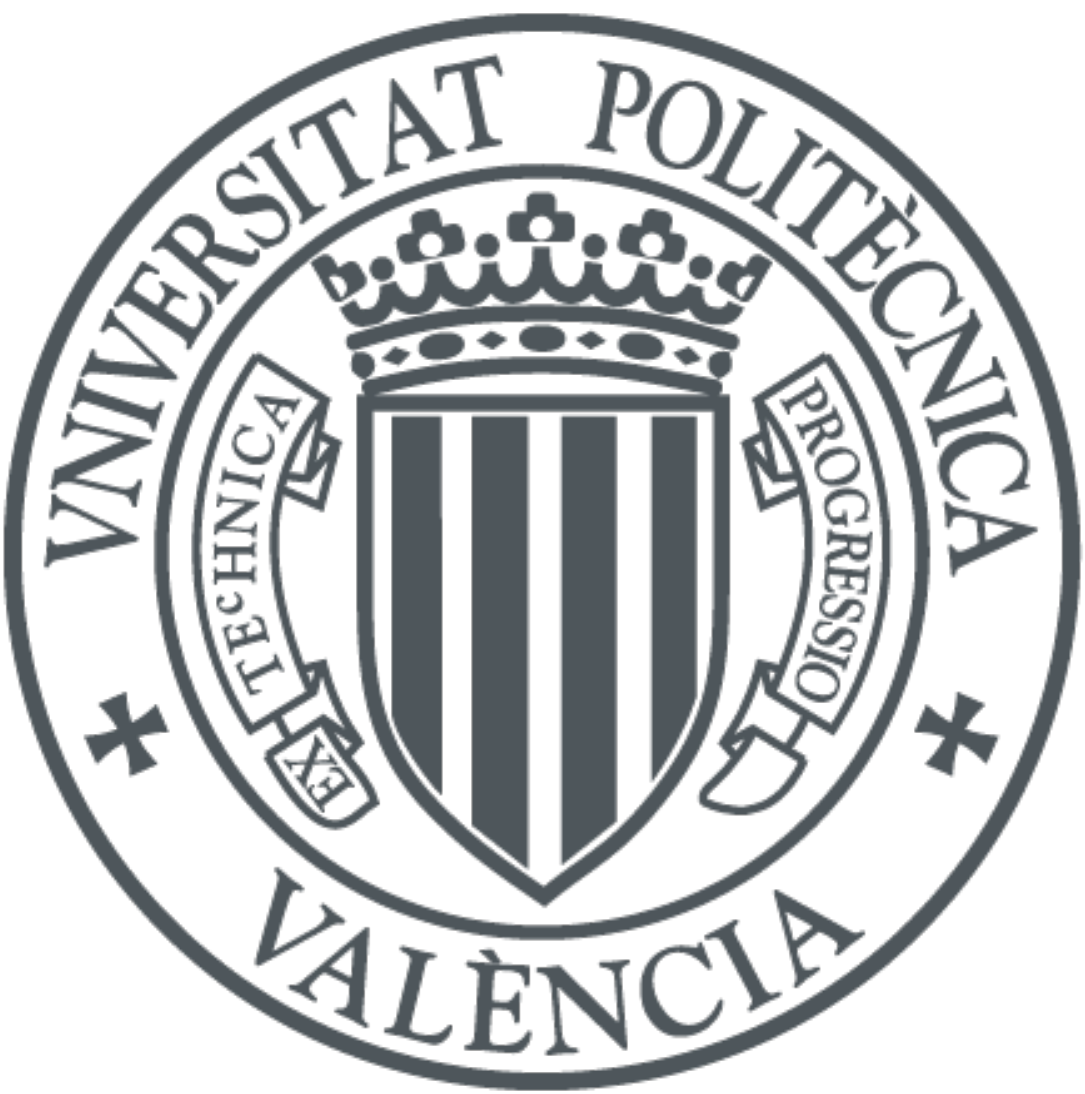

The final publication is available at

https://dx.doi.org/10.1016/j.fbio.2014.01.002

Copyright Elsevier

Additional Information 


\section{INFLUENCE OF DRYING METHOD AND EXTRACTION VARIABLES ON THE ANTIOXIDANT PROPERTIES OF PERSIMMON LEAVES}

Martínez-Las Heras, R., Heredia, A., Castelló, M.L., Andrés, A.

Food Bioscience 6: 1-8 (2014)

\section{ABSTRACT}

The presence of antioxidant compounds and therefore the antioxidant capacity of persimmon leaves and their extracts have been reported by many authors. Furthermore, it is known that both the method of drying and the temperature at which this process takes place substantially affect the properties of the final product. However, there are no studies in the literature that examine how drying variables can affect the quality of persimmon leaves, especially as refers to preservation of their antioxidant properties. Therefore, the aim of this paper was to compare some antioxidant properties of aqueous extracts of persimmon leaves obtained under different drying methods (shade drying, hot air drying at 100 and $180{ }^{\circ} \mathrm{C}$, and freeze drying) and infusion conditions ( 70,80 and $90{ }^{\circ} \mathrm{C}$ for $1,3,5,60$ and $\left.1440 \mathrm{~min}\right)$. The results in terms of total phenol content, flavonoids and antioxidant capacity indicated that air drying at $100{ }^{\circ} \mathrm{C}$ would be the optimal process for the stabilization of persimmon leaves, and their subsequent use in brewed beverages. Likewise, the best conditions of aqueous extraction in order to maximize the extractability of antioxidant compounds corresponded to $90{ }^{\circ} \mathrm{C}$ for $60 \mathrm{~min}$. A short experiment performed in this study confirmed that small persimmon leaves (axial axis: $9 \pm 1(\mathrm{~cm})$; equatorial axis: $7.0 \pm 0.9(\mathrm{~cm}))$ had around $9 \%$ more flavonoids, and $7 \%$ more total phenolic content and antioxidant capacity than the large ones (axial axis: $17 \pm 2(\mathrm{~cm})$; equatorial axis: $10 \pm 1(\mathrm{~cm})$ ).

Keywords: persimmon leaves; drying method; antioxidant properties; leaf size

\section{INTRODUCTION}


The presence of natural antioxidants in food is important, not only because they are responsible for the organoleptic characteristics of the products but also because they may play an important role in helping to prevent diseases such as cancer, cardiovascular disease, Alzheimer's disease and macular degeneration (Peter, Wootton-Beard, \& Ryan, 2011). Most antioxidants (vitamin C, vitamin E, carotenoids, glucosinolates and polyphenols among others) are found in fruit and vegetables (Wang, Melnyka, Tsao, \& Marcone, 2011). Polyphenols, compounds which are biosynthesized by plants, are responsible for most of the antioxidant activity of fruits and vegetables and some natural teas and beverages. From a chemical point of view, polyphenols have at least one or more hydroxyl group (OH-) attached to an aromatic ring in their structure. While all polyphenols present antioxidant properties, it has been established that some of these compounds also show anti-carcinogenic (Birt, Hendrich, \& Wang, 2001), anti-inflammatory, antiviral, anti-allergic (Larson, 1988) and anti-bacterial properties (Piccaglia, Marotti, Giovanelli, Deans, \& Eaglesham, 1993). They also exhibit estrogenic activity, modulation of the activity of numerous enzymes, including digestive enzymes, prevention of coronary diseases, as well as age-related degenerative brain disorders (Parr \& Bolwell, 2000) and have beneficial effects on homeostasis, constipation, hypertension, apoplexy and atherosclerosis (Kotani et al., 2000, Matsumoto et al., 2002, Tanaka et al., 2003 and Sakanaka et al., 2005).

Beverages and herbal teas (infusions) are drunk habitually for their flavor but also, because they deliver high concentrations of functional bioactive compounds with antioxidant properties (Shahidi, 2000). In Japan, kakinoha-cha (Japanese persimmon leaf tea) is infused with hot (rather than boiling) water, drunk like green tea and used traditionally due to its healing properties (treatment of paralysis, frostbite, burns and to stop bleeding) (Matsuo and Ito, 1978). Their principal compounds are flavonoid oligomers, tannins, phenols, organic acids, chlorophyll, vitamin C and caffeine (Matsuo and Ito, 1978 and Jo et al., 2003). In 
addition, persimmon trees are deciduous; therefore, making use of their leaves could be a good way to increase the economic value of this crop. Once collected, the leaves need to be stabilized, usually by drying, before their use. Dry persimmon leaves could be used in hot water infusions or as a new source of antioxidants. These antioxidants could be incorporated, once extracted, into other food matrices such as beverages, biscuits, etc. Knowing the influence of different treatments on the bioactive compounds of these leaves is important to optimize their extraction. However, there are only a limited number of publications (Sun et al., 2011, Sakanaka et al., 2005, Jo et al., 2003 and Lee et al., 2006) that yield information about the characterization of persimmon leaves in terms of bioactive compounds and antioxidant benefits, and there are none on the effect of different drying techniques on these compounds.

Drying is a very common preservation method used in foodstuffs and the quality of the final products is strongly dependent on the technique and the process variables used (Doymaz, 2005). The reduction of water activity by moisture removal also implies significant reduction of weight and volume, minimizing packaging, transportation and storage costs (Okos, Narsimhan, Singh, \& Witnauer, 1992).

The food industry has evolved and often carries out freeze and air-drying processes, under controlled conditions, to achieve the objective of long-term storage. However, the health-promoting capacity and nutritional characteristics of plant products depend on the type of processing employed. Some studies report that freeze-drying increases the extraction of bioactive compounds of different products in comparison to air drying (Pinela et al., 2012, Kwok et al., 2004 and Dorta et al., 2012). This is because freezedrying is based on the dehydration by sublimation of a frozen product (Ratti, 2001). Nevertheless, freeze-drying has always been recognized as the most expensive process for manufacturing a dehydrated product and its application depends 
on the uses of the final product. Moreover, temperature and time are crucial variables to consider in this kind of process.

The objective of this study was to analyze the influence of the drying techniques (shade-drying, hot air drying and freezedrying) on the antioxidant compounds and colour of persimmon leaf infusions obtained with different times (1, 3, 5, 60 and 1440 min) and temperatures $\left(70,80\right.$ and $\left.90^{\circ} \mathrm{C}\right)$ of infusion. A short study about the influence of leaf size on antioxidant properties was also performed.

\section{MATERIALS AND METHODS}

\subsection{Materials and chemicals}

Persimmon leaves (Diospyros. kaki, Rojo Brillante var.) were harvested in mid-October 2012 from 10 trees in an orchard in Valencia (Spain). The cultivar used was "Rojo Brillante". FolinCiocalteu reagent, sodium nitrite, 2,2-diphenyl-1-picrylhydrazyl, 6-Hydroxy-2,5,7,8-tetramethylchroman-2-carboxylic acid, gallic acid, L-ascorbic acid and (+)- Catechin were obtained from Sigma-Aldrich Co. Sodium carbonate, 2,6dichlorophenolindophenol Sodium Salt 2-hydate (DIP), metaPhosphoric Acid stabilized with $\mathrm{NaPO}_{3}$, sodium hydroxide solution were from Panreac. Aluminum chloride hexahydrate was from Fluka and methanol from Scharlab.

\subsection{Drying treatments of raw material}

In order to evaluate the effect of drying techniques on the antioxidant properties of persimmon leaves, the raw material was blanched in hot water $\left(100^{\circ} \mathrm{C}\right)$ for 1 min and after, it was subjected to three different drying methods: (i) shade-drying in which leaves were dried on trays at $20^{\circ} \mathrm{C}$ for 30 days; (ii) hot air drying at $100^{\circ} \mathrm{C}$ and $180^{\circ} \mathrm{C}$ for $30 \mathrm{~min}$ in a convective drier; (iii) freeze-drying at vacuum pressure of $10^{-1}$ mbar for 24 hours.

Dried persimmon leaves were grounded to a fine powder (particle size $\leq 1 \mathrm{~mm}$ ) in a SEVERIN mill previous to aqueous extraction. 


\subsection{Aqueous extraction from persimmon leaves}

Aqueous extraction of persimmon leaves was performed with a product to water ratio of $1: 10(\mathrm{w} / \mathrm{w})$ at 70,80 and $90^{\circ} \mathrm{C}$ for $1,3,5$, 60 and $1440 \mathrm{~min}$. The extracts were filtered with Whatman filter paper (particle retention: $20-25 \mu \mathrm{m}$ ) and cooled to $25^{\circ} \mathrm{C}$ before analysis.

\subsection{Influence of leaf size on antioxidants properties}

In order to study the influence of leaf size on antioxidant properties, an additional short study was performed in two different leaf sizes. For this purpose, leaves were classified into two groups: small leaves (axial axis: $9 \pm 1(\mathrm{~cm})$; equatorial axis: $7.0 \pm 0.9(\mathrm{~cm})$ ) and large leaves (axial axis: $17 \pm 2(\mathrm{~cm})$; equatorial axis: $10 \pm 1(\mathrm{~cm})$ ) and they were subjected to a blanching at $100^{\circ} \mathrm{C}$ for $1 \mathrm{~min}$ followed by a hot air drying at $100^{\circ} \mathrm{C}$ until constant weight. The antioxidant properties of persimmon leaves with regard to leaf size were analyzed after aqueous extraction at $90^{\circ} \mathrm{C}$ for 5 min with a product to water ratio of $1: 10$ $(w / w)$. The extracts were filtered with Whatman filter paper (particle retention: $20-25 \mu \mathrm{m}$ ) and cooled to $25^{\circ} \mathrm{C}$ before analysis.

\subsection{Analytical determinations}

All analytical determinations were performed in triplicate for each extract.

\subsubsection{Moisture}

Moisture was estimated with the AOAC (2000) official method (number 934.01).

\subsubsection{Determination of total phenolic content}

Samples were analyzed spectrophotometrically, with a modified Folin-Ciocalteu method (Sakanaka et. al, 2005), in order to determine the total phenolic content. $0.5 \mathrm{ml}$ of distilled water and 
$0.125 \mathrm{ml}$ of a known dilution of the extract were added to a cuvette followed by the addition of $0.125 \mathrm{ml}$ of Folin-Ciocalteu reagent. The mixture was shaken and $1.25 \mathrm{ml}$ of a $7 \%$ sodium carbonate solution and $1 \mathrm{ml}$ of distilled water were added after 6 $\mathrm{min}$. The color was left to develop for $90 \mathrm{~min}$ and the absorbance was measured at $760 \mathrm{~nm}$ using a spectrophotometer (JASCO V630). The measurement was compared to a standard curve of gallic acid solutions and expressed as $\mathrm{mg}$ of gallic acid equivalents per gram of dry matter ( $\mathrm{mg} \mathrm{GA} / \mathrm{g} \mathrm{d}$. m.). A blank was prepared in the same way but without any sample.

\subsubsection{Determination of total flavonoid content}

Total flavonoid content was determined using the modified colorimetric method described by Dewanto, $\mathrm{Wu}$, Adom, and Liu (2002). $0.25 \mathrm{ml}$ of the extract was mixed with $1 \mathrm{ml}$ of distilled water in a cuvette, followed by the addition of $0.075 \mathrm{ml}$ of a $5 \%$ sodium nitrite solution. After $6 \mathrm{~min}, 0.15 \mathrm{ml}$ of a $10 \%$ aluminum chloride solution was added and the mixture was allowed to stand for a further $5 \mathrm{~min}$ before $0.5 \mathrm{ml}$ of $1 \mathrm{M}$ sodium hydroxide solution was added. Finally, $2 \mathrm{ml}$ of distilled water was added and the absorbance was measured immediately at $510 \mathrm{~nm}$ using a UV/vis spectrophotometer (JASCO V-630). The measurement was compared to a standard curve of $(+)$-catechin solutions and expressed as $\mathrm{mg}$ of $(+)$-catechin equivalents per gram. A blank was prepared in the same way but without sample.

\subsubsection{DPPH radical-scavenging activity}

The antioxidant activity (AA) of the extract was measured on the basis of the scavenging activities of the stable 2,2-diphenyl-1picrylhydrazyl free radical as described by Shahidi, LiyanaPathirana, and Wall (2006) with some modifications. According to this method, the purple colour intensity of 2,2-diphenyl-1picrylhydrazyl (DPPH) solution decays in the presence of an antioxidant, and this absorbance change is measured spectrophotometrically at $515 \mathrm{~nm}$. 
A $0.1 \mathrm{ml}$ of the sample diluted in methanol $(5 \mathrm{ml}$ extract/ $25 \mathrm{ml}$ methanol) was added to $3.9 \mathrm{ml}$ of a methanolic solution of DPPH (80:20; methanol:water) $(0.025 \mathrm{mg} / \mathrm{ml})$. The solution was shaken and after $30 \mathrm{~min}$ the absorbance of the sample was measured at $515 \mathrm{~nm}$ using methanol as a blank. The antioxidant activity (\%) of the samples was calculated according to Eq. (1):

$$
\operatorname{AA}(\%)=\frac{A_{t=0}-A_{t=30}}{A_{t=0}} \times 100
$$

where $A_{t=0}$ is the initial absorbance of the DPPH (without sample) and $A_{t=30}$ is the absorbance of the sample after $30 \mathrm{~min}$. The measurement was compared to a standard curve of Trolox (6Hydroxy-2,5,7,8-tetramethylchroman-2-carboxylic acid) solutions and expressed as mg of Trolox per gram.

\subsubsection{Optical properties}

The CIELAB color space was studied, the following color coordinates were determined by transmittance: lightness $\left(L^{*}\right)$, redness $\left(a^{*}, \pm\right.$ red-green) and yellowness $\left(b^{*}, \pm\right.$ yellow-blue) . Color determinations were made, at $20 \pm 2^{\circ} \mathrm{C}$ by means of a Minolta, mod. CM- 3600d, spectrophotometer with illuminant D65 and $10^{\circ}$ observer.

\subsection{Statistical analysis}

Statistical analysis of variance (ANOVA) was performed by Statgraphics Centurion to estimate the effect of process variables (type of drying method, temperature and time of infusion and leaf size) on the obtained results. Evaluations were based on a $95 \%$ of significance level.

\section{RESULTS AND DISCUSSION}

3.1. Influence of drying method on the degradation and extractability of antioxidant compounds 
The stabilization of the leaves by drying processes involves changes in the matrix that can affect not only the concentration of antioxidant compounds in the dry product but also the extractability thereof. For this reason, the concentration of total phenols and flavonoids, and antioxidant capacity was assessed in aqueous extracts of fresh and dried leaves obtained by different drying processes. For a better comparison of the results, the values have been stated in terms of grams of dry matter (Table 1) and they correspond to 1440 minutes of extraction. No statistical differences were found between antioxidant contents and antioxidant activity after 60 and 1440 minutes of extraction, this confirming that the equilibrium of extraction was achieved (data not shown).

The results of the study showed that the degradation of flavonoids varied with the different drying treatments applied to the samples. It is noted that regardless of the type of drying, extracts of dried leaves always showed lower concentrations of flavonoids than those from fresh leaves. The loss of flavonoids during drying might be due to the process conditions, in particular the temperatures and the duration used (Schieber, Stintzing, \& Carle, 2001). The loss of flavonoids was found to be lower with Air Drying at $100^{\circ} \mathrm{C}$ and Freeze Drying, than Air Drying at $180^{\circ} \mathrm{C}$ and Shade Drying. The degradation of phytochemicals upon thermal treatments has been reported by many authors (Zhang \& Hamauzu, 2004; Puupponen-Pimiä, Nuutila, Aami, \& OksmanCaldentey, 2003; Volden et al., 2008). Davey et al. (2002) found that thermal processing can affect the phytochemicals by thermal breakdown, which affects the integrity of cell structure, thereby resulting in the migration of components, leading to breakdown by various chemical reactions involving enzymes, light and oxygen.

In the case of total phenols, a higher concentration was found in dry leaf extracts (Table 1). This result could be related to an increase in the extractability of such compounds as a consequence of the matrix changes during the drying process. 
The structure of dry leaves is more open and interconnected than in fresh leaves, meaning that the solvent can penetrate more easily, providing a greater surface for mass transfer, and resulting in a more efficient extraction of these compounds. As a result of this increase in the extractability of the phenolic compounds, higher values of antioxidant activity were obtained for dry leaves. However, the extracts obtained at $90^{\circ} \mathrm{C}$ from fresh leaves had the highest values, probably due to the higher concentration of flavonoids in these samples. 
Table 1. Total phenols, flavonoids and antioxidant activity of persimmon leaf extracts from fresh and dried leaves with different infusion temperatures. Significant differences as determined by ANOVA ( $p<$ 0.05 ) are indicated by different letters

\begin{tabular}{ccccc}
\hline $\begin{array}{c}\text { Drying } \\
\text { method }\end{array}$ & $\mathrm{T}\left({ }^{\circ} \mathrm{C}\right)$ & $\begin{array}{c}\text { Phenols } \\
\text { (mg GA/g d. m. })\end{array}$ & $\begin{array}{c}\text { Flavonoids } \\
\text { (mg catechin/ g d. m. })\end{array}$ & $\begin{array}{c}\text { Antioxidant activity } \\
\text { (mg trolox/ g d. m. })\end{array}$ \\
\hline \multirow{3}{*}{ Fresh leaves } & 70 & $59(2) \mathrm{h}$ & $52(3) \mathrm{f}$ & $105(6) \mathrm{h}$ \\
& 80 & $67(2) \mathrm{d}$ & $57.7(1.4) \mathrm{g}$ & $125(2) \mathrm{d}$ \\
& 90 & $78(2) \mathrm{i}$ & $62(3) \mathrm{h}$ & $190(9) \mathrm{i}$ \\
AD-100 & 70 & $85(3) \mathrm{a}$ & $25(2) \mathrm{a}$ & $148.8(0.3) \mathrm{a}$ \\
& 80 & $99(2) \mathrm{b}$ & $34.60(1.07) \mathrm{b}$ & $164(5) \mathrm{b}$ \\
AD-180 & 90 & $106.0234(1.1018) \mathrm{c}$ & $34.4(1.4) \mathrm{b}$ & $170(2) \mathrm{c}$ \\
& 70 & $67.4(0.3) \mathrm{d}$ & $21(2) \mathrm{ac}$ & $124.100(1.002) \mathrm{d}$ \\
& 80 & $85.28(1.14) \mathrm{a}$ & $26(4) \mathrm{ad}$ & $138.6(0.7) \mathrm{e}$ \\
FD & 90 & $88(3) \mathrm{e}$ & $27.6(1.2) \mathrm{d}$ & $146(5) \mathrm{af}$ \\
& 70 & $81(3) \mathrm{f}$ & $26(2) \mathrm{a}$ & $125(3) \mathrm{d}$ \\
& 80 & $83.48(1.04) \mathrm{a}$ & $28.1(1.2) \mathrm{ad}$ & $141(3) \mathrm{ef}$ \\
& 90 & $92(2) \mathrm{g}$ & $32(3) \mathrm{e}$ & $153(4) \mathrm{ag}$ \\
& 70 & $61(2) \mathrm{h}$ & $21(2) \mathrm{c}$ & $108(4) \mathrm{h}$ \\
& 80 & $72(2) \mathrm{j}$ & $23(2) \mathrm{ac}$ & $112(5) \mathrm{h}$ \\
& 90 & $76.6(1.3) \mathrm{e}$ & $27.4(0.6) \mathrm{ad}$ & $116(3) \mathrm{k}$ \\
\hline
\end{tabular}


3.2. Influence of infusion time and temperature on the extraction of antioxidant compounds

Fig. 1 shows the total phenolic concentration of the aqueous extracts of persimmon leaves dried under different conditions, considering time of infusion and water temperature. The extraction kinetic of phenols was very rapid in all cases, taking place during the first few minutes of the infusion and remaining constant between $60 \mathrm{~min}$ (Fig. 1) and $1440 \mathrm{~min}$ (Table 1). Regarding to the effect of temperature, the higher the temperature of infusion the higher the phenolic concentration of the extracts. Also, the effect of temperature is observed on both, the kinetics and the concentrations achieved at $1440 \mathrm{~min}$ of infusion (Table 1). These results are consistent with the fact that the drying method and processing conditions greatly affect not only the degradation of bioactive compounds but also their stability and extractability. This is because method, temperature and drying time are process variables that significantly affect the structure of the resultant matrix, regardless of whether the final humidity or water activity is the same. Water removal during the drying of plant material is accompanied by significant deformation, which degrades the vegetal matrix and the functionality of its cell walls and membranes. The varying disintegration of this matrix results in a greater or lesser exposure of antioxidant compounds to oxidation reactions, hence the importance of establishing the most suitable drying conditions in each case.

The results obtained (Fig. 1) show the great influence of the drying method on the extraction of phenols during infusion. The extracts from leaves dried with air at $100^{\circ} \mathrm{C}(\mathrm{AD}-100)$ gave the highest total phenolic concentration, followed by extracts from lyophilized leaves (FD), and then the extracts from air dried leaves at $180^{\circ} \mathrm{C}(\mathrm{AD}-180)$ and from shade dried leaves (SD). 

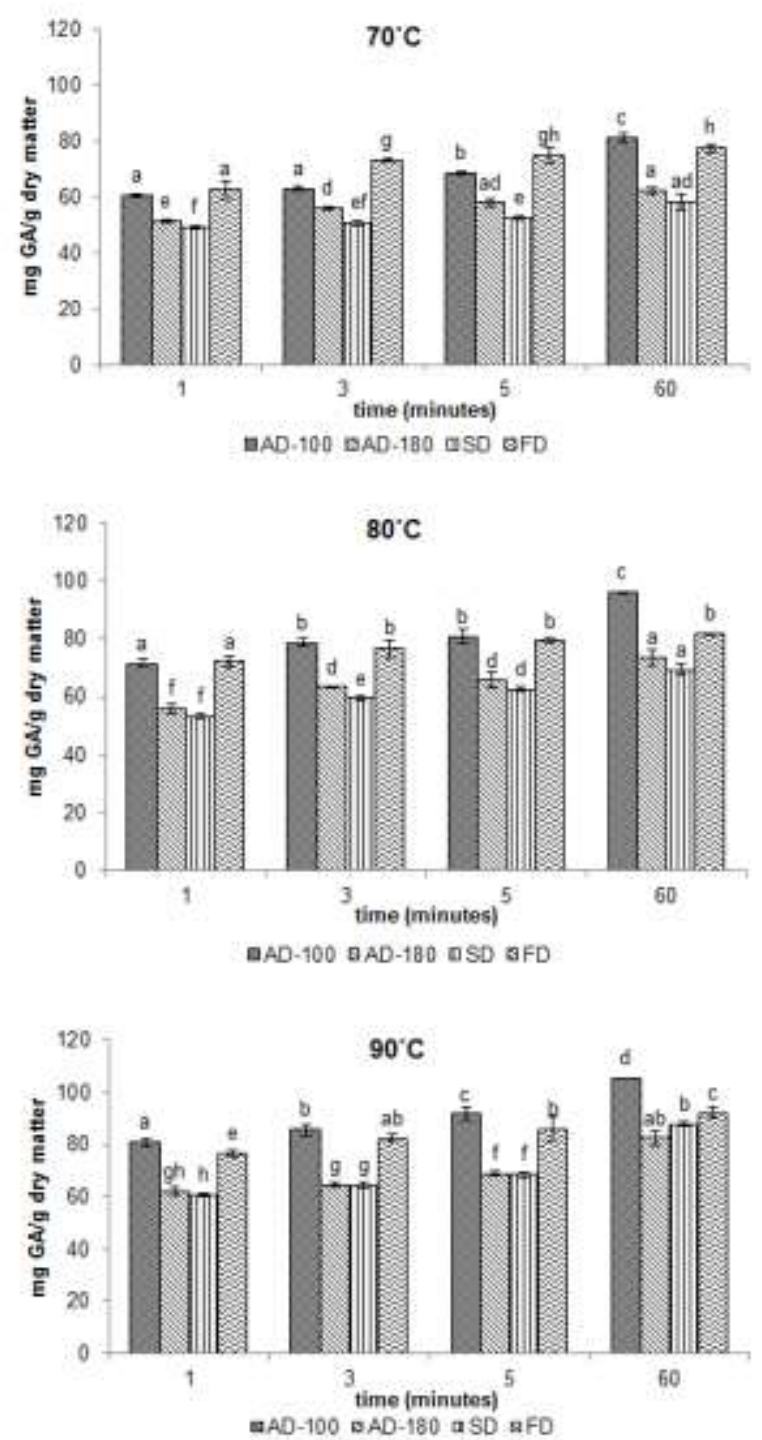

Fig. 1 - Effect of drying method, infusion time and infusion temperature on the total phenolic content (mg gallic acid/g dry matter) of the extracts. Significant differences as determined by ANOVA $(p<0.05)$ are indicated by different letters. 
Lyophilization is often considered to be the most adequate drying technique for preserving temperature sensitive compounds. However, it is an expensive method which is not suitable for large productions in continuous processes. In the case of persimmon leaves, it would not be a competitive process for preserving phenols since similar or better results are obtained with air drying at $100^{\circ} \mathrm{C}(\mathrm{AD}-100)$. Likewise, shade drying, which is widely used in countries producing tea and herbal teas, is cheap but has some drawbacks such as the drying time, the space required and the manpower required, etc. In view of the results obtained in this study, it could be said that the long drying time needed and the low processing temperatures involved in shade drying imply a greater exposure of the material to enzymatic and oxidation reactions than the other methods studied.

The same tendency is observed when the influence of the different processing variables (drying method, time and temperature of infusion) on the concentration of flavonoids and the antioxidant capacity of the extracts is analyzed (Fig. 2 and 3).

The antioxidant properties of food matrices are due to the presence of a complex mixture of compounds of varying polarity, such as vitamin $\mathrm{C}$, vitamin $\mathrm{E}$, carotenoids, and polyphenols (Cantin, Moreno \& Gogorcena, 2009). When these compounds are extracted in aqueous media, the antioxidant capacity of the extracts depends on the type and quantity of the compounds extracted during infusion, and therefore it could be correlated with values of total phenols and flavonoids contents obtained in those extracts. The results obtained in this work show a good correlation between the concentration of flavonoids and total phenols and antioxidant activity, although higher values of $r^{2}$ were obtained for the correlation between flavonoids and antioxidant capacity (Table 2). 

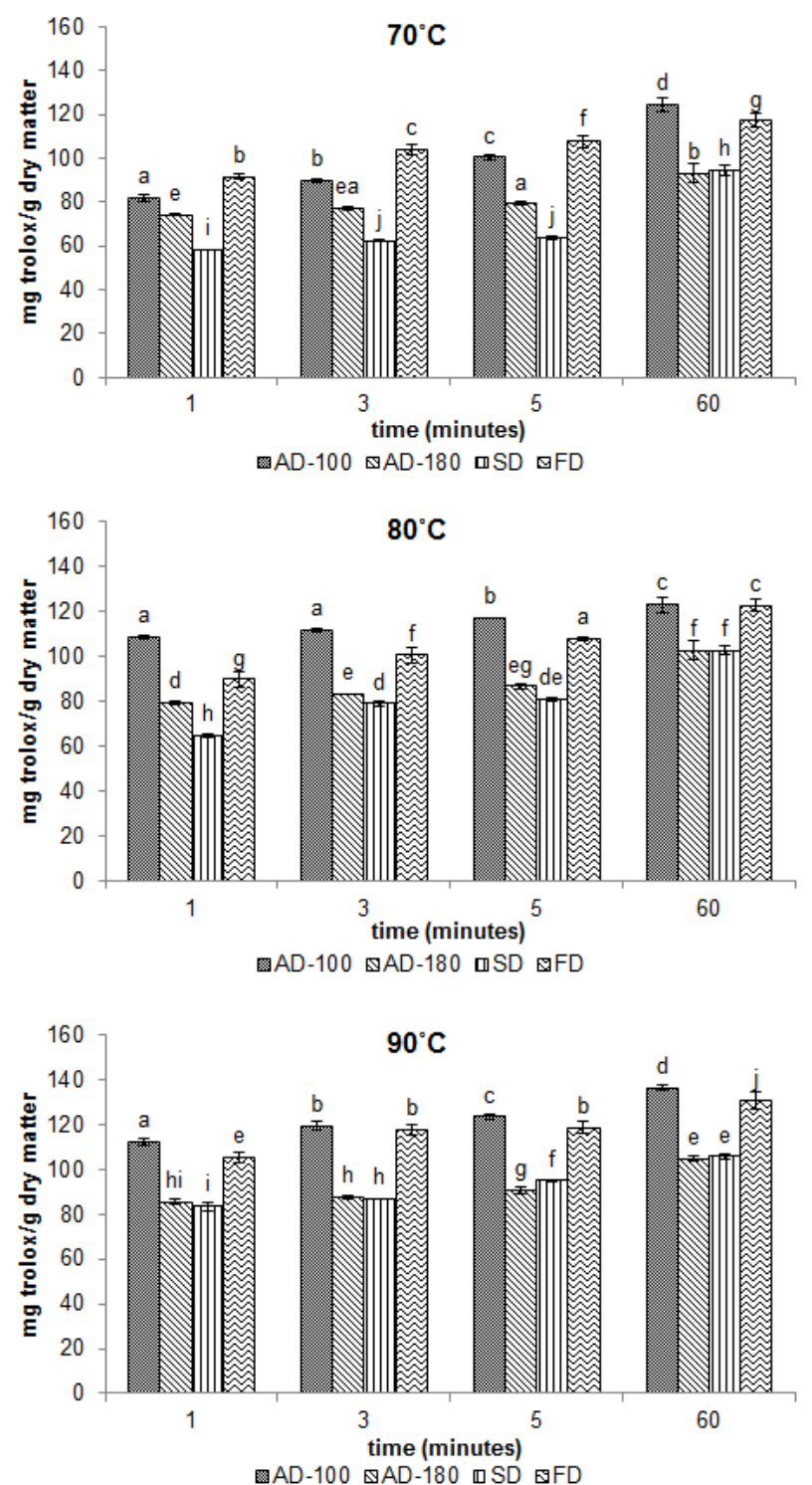

Fig. 2 - Effect of driying method, infusion time and temperature on the antioxidant capacity (mg trolox/ g dry matter) of the extracts. Significant differences as determined by ANOVA $(p<0.05)$ are indicated by different letters. 

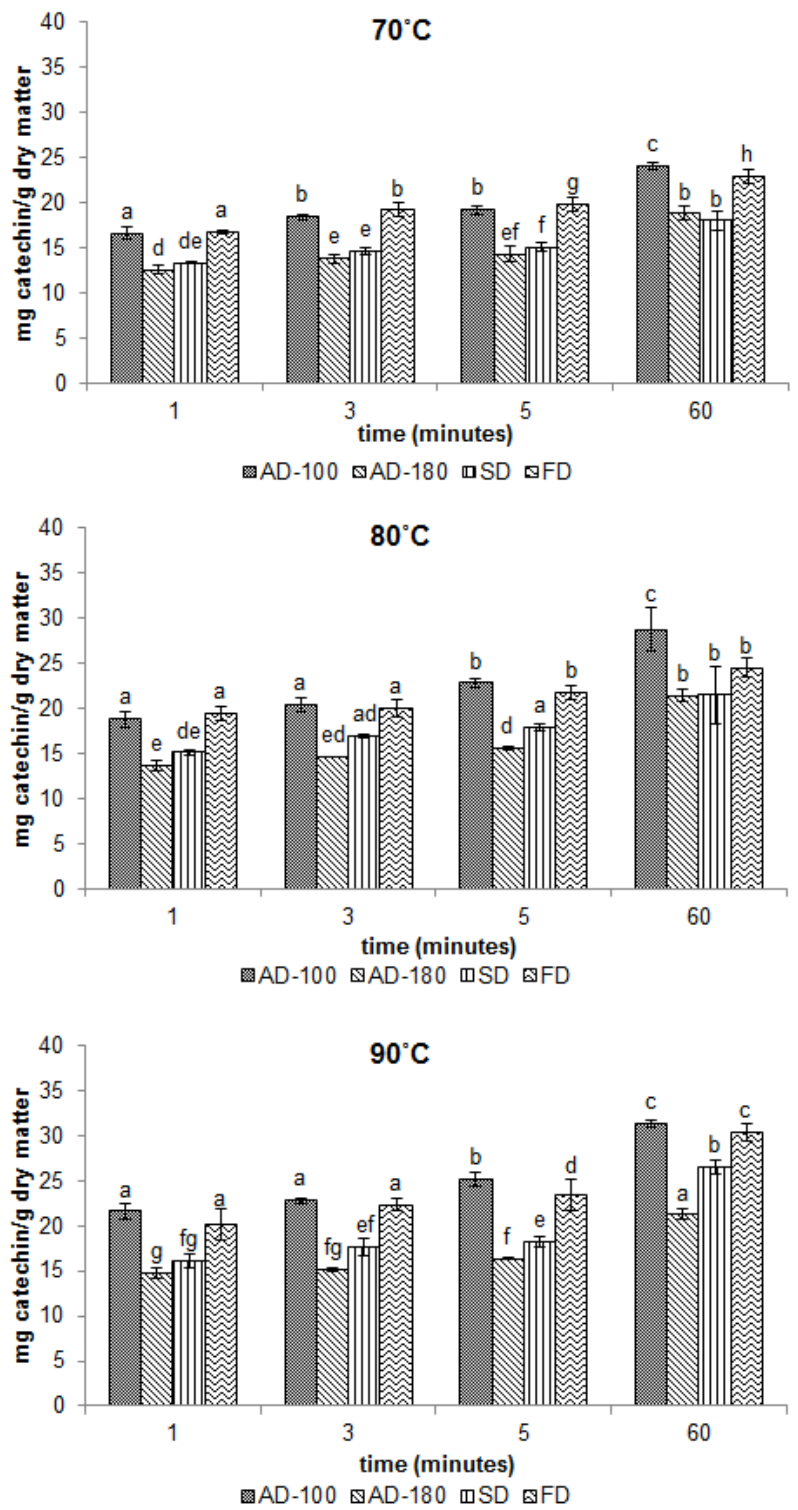

Fig. 3 - Effect of driying method, infusion time and temperature on the flavonoids ( $\mathrm{mg}$ catechin/ $\mathrm{g}$ dry matter) of the extracts. Significant differences as determined by ANOVA $(p<0.05)$ are indicated by different letters. 
Table 2. Correlation coefficients $\left(r^{2}\right)$ between total phenols vs. antioxidant capacity and flavonoids vs. antioxidant capacity, calculated from the results presented in Fig. 1, 2 and 3.

\begin{tabular}{cccc}
\hline \multirow{2}{*}{$\begin{array}{c}\text { Drying } \\
\text { method }\end{array}$} & $\begin{array}{c}\text { T infusion } \\
\left({ }^{\circ} \mathrm{C}\right)\end{array}$ & $\begin{array}{c}\text { Antioxidant } \\
\text { activity vs. } \\
\text { flavonoids }\end{array}$ & $\begin{array}{c}\text { Antioxidant } \\
\text { activity vs. } \\
\text { phenols }\end{array}$ \\
\hline \multirow{3}{*}{ AD-100 } & 70 & 0.9490 & 0.9546 \\
& 80 & 0.8636 & 0.6471 \\
& 90 & 0.8761 & 0.7186 \\
\hline \multirow{3}{*}{ AD-180 } & 70 & 0.8983 & 0.8506 \\
& 80 & 0.9372 & 0.9323 \\
& 90 & 0.9649 & 0.8038 \\
\hline \multirow{2}{*}{ FD } & 70 & 0.9603 & 0.9261 \\
& 80 & 0.9781 & 0.8925 \\
& 90 & 0.8585 & 0.8608 \\
\hline \multirow{2}{*}{ SD } & 70 & 0.9724 & 0.9756 \\
& 80 & 0.9929 & 0.9718 \\
& 90 & 0.9188 & 0.9241 \\
\hline
\end{tabular}

3.3. Influence of drying method, infusion time and temperature on the colour of persimmon leaf extracts

According to the multivariant analysis of variance (ANOVA), both drying method and time of infusion, as well as their interaction, had a significance statistical influence on CIEL ${ }^{*} a^{*} b^{*}$ colour parameters; while no influence of temperature of infusion was found on them (data not shown). Fig. 4 showed the values of $L^{*}$, $a^{*}$ and $b^{*}$ of the persimmon leaf extracts in the colorimetric planes $L^{*} a^{*}$ y $b^{*} a^{*}$ as a function of drying method and time infusion at a set temperature of infusion of $90^{\circ} \mathrm{C}$. A loss of lightness $\left(L^{*}\right)$ and an increase of $b^{*}$ and $a^{*}$ values was found as time of infusion progressed, being especially notable after 1440 minutes. The change of $a^{*}$ coordinate from negative to positive values indicates a turn of colour from green-yellowish to brownyellowish ones. Regarding to the effect of drying method, no statistical significance effect of drying method were found among 
the colour of the samples at 1, 3 and 5 min of infusion; whereas infusions from freeze dried leaves at 60 and 1440 min presented higher lightness and lower $a^{*}$ and $b^{*}$ values than infusions obtained from shade dried leaves, and above all than infusions from air dried ones. Therefore, infusions obtained from air dried persimmon leaves are characterized by a more dark and brownyellowish colour, while higher luminosity and green-yellowish colour is in infusions made with freeze dried leaves.

3.4. Influence of leaf size on the total phenolic content, flavonoids and antioxidant capacity

Given the heterogeneity of the size of persimmon leaves, the total phenolic content, flavonoids and antioxidant capacity were analyzed in two leaf sizes to determine if significant differences can be attributed to leaf size (Table 3). The smaller leaves presented around $9 \%$ more flavonoids, and $7 \%$ more total phenolic content and antioxidant capacity than the large leaves; in all cases the differences were statistically significant. The average values were lower than those obtained by Sakanaka et al. (2005) in all cases, while the values of antioxidant activity were higher than those obtained by Sun et al. (2011). These differences can be attributed to differences in variety, harvesting time and the extraction conditions used in each case. However, since in the present study the extraction of compounds was performed under the same conditions, the values obtained permitted evaluation of the differences between the two leaf sizes. These results may be useful to establish the criteria for collecting the persimmon leaves, in order to obtain a product for infusion with better antioxidant properties. 


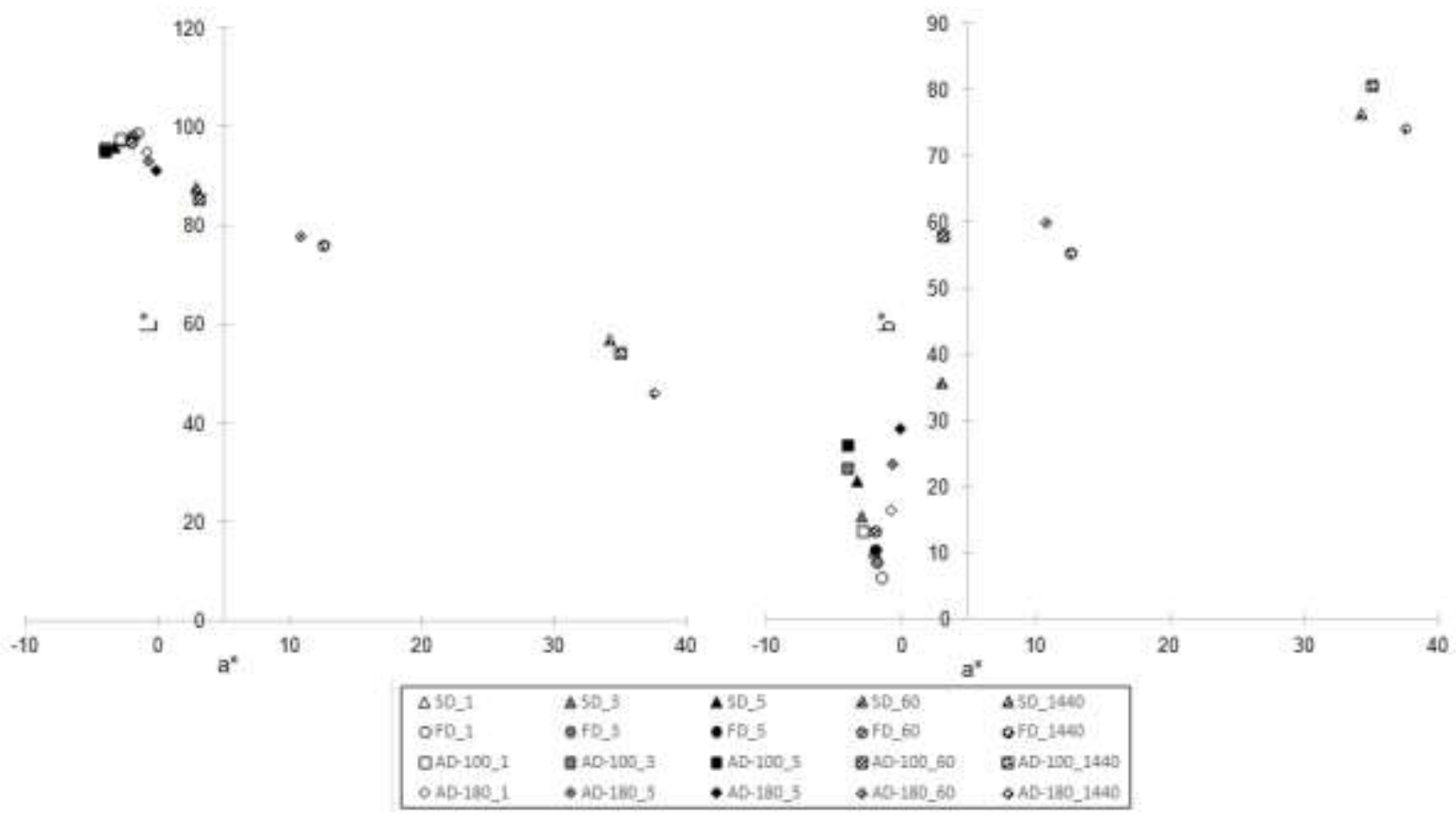

Fig. 4 - Influence of drying method and infusion time on $L^{*}, a^{*}$ and $b^{*}$ coordinates parameters (mean values) of persimmon leaf extracts obtained at a set infusion temperature of $90^{\circ} \mathrm{C}$. (For interpretation of the references to color in this figure legend, the reader is referred to the web version of this article.) 
Table 3. Total phenols and flavonoids contents, as well as antioxidant activity, of aqueous extracts of persimmon leaves with two different sizes. Significant differences as determined by ANOVA $(p<0.05)$ are indicated by different letters.

\begin{tabular}{cc|ccc}
\hline \multicolumn{2}{c|}{ Leave Size } & \multirow{2}{*}{$\begin{array}{c}\text { Total Phenols } \\
\text { mg GA/g dry matter }\end{array}$} & $\begin{array}{c}\text { Flavonoids } \\
\text { mg catechin/g dry matter }\end{array}$ & $\begin{array}{c}\text { Antioxidant activity } \\
\text { mg trolox/g dry matter }\end{array}$ \\
\cline { 1 - 2 } $\begin{array}{ccccc}\text { Axial Axis } & \text { Equatorial } \\
\text { (cm) }\end{array}$ & Axis $(\mathbf{c m})$ & & & \\
\hline $9 \pm 1$ & $7.0 \pm 0.9$ & $83 \pm 4(\mathrm{a})$ & $30,8 \pm 0,5(\mathrm{a})$ & $118 \pm 3(\mathrm{a})$ \\
$17 \pm 2$ & $10 \pm 1$ & $77 \pm 4(\mathrm{~b})$ & $27,9 \pm 0,7(\mathrm{~b})$ & $109,61 \pm 1,08(\mathrm{~b})$ \\
\hline
\end{tabular}




\section{CONCLUSIONS}

Proper drying of persimmon leaves (D. kaki, Rojo Brillante var.) can be considered as an alternative use of the crop, due to the antioxidant properties of aqueous extracts. Hot air drying at $100^{\circ} \mathrm{C}$ yields better antioxidant levels compared to air drying at $180^{\circ} \mathrm{C}$, drying in the shade or lyophilization. Also, the size of leaf seems to have a significant influence on the content of flavonoids and total phenols, so this aspect should be studied more in deep in order to define and to establish the optimal harvesting process.

\section{ACKOWLEDGEMENTS AND CONFLICT OF INTEREST STAMENTS}

The authors acknowledge the support of the Universtitat Politècnica de València and certify that there is no conflict of interest with any financial organization regarding the material discussed in the manuscript.

\section{REFERENCES}

AOAC (2000). Official method of analysis (16 th ed.). Association of Official Analytical Chemists: Washington DC.

Birt, D.F.; Hendrich, S.; Wang,W. (2001). Dietary agents in cancer prevention: flavonoids and isoflavonoids. Pharmacology and Therapeutics, 90, 157-177.

Cantin, C. M.; Moreno, M. A.; Gogorcena, Y. (2009). Evaluation of the antioxidant capacity, phenolic compounds, and vitamin c content of different peach and nectarine Prunus persica (L.) batsch breeding progenies. Journal of Agricultural and Food Chemistry, 57(11), 4586-4592.

Dewanto, V.; Wu, X.; Adom, K. K.; Liu, R.H. (2002). Thermal processing enhances the nutritional value of tomatoes by increasing total antioxidant activity. Journal of Agricultural and Food Chemistry, 50, 3010-3014. 
Dorta, E; Lobo, M. G.; González, M. (2012). Using drying treatments to stabilise mango peel and seed: Effect on antioxidant activity. LWT - Food Science and Technology,45, 261-268.

Doymaz, I. (2005). Drying behaviour of green beans. Journal of Food Engineering, 69, 2, 161-165.

Davey, M. W.; Van Montagu, M.; Inze, D.; Sanmartin, M.; Kanellis, A.; Smirnoff, N.; Benzie, I. J. J.; Strain, J. J.; Favell, D.; Fletcher, J. (2003). Plant I-ascorbic acid: Chemistry, function, metabolism, bioavailability and effects of processing. Journal of the Science of Food and Agriculture, 80, 825-860.

Jo, C.; Son, J.H.; Shin, M.G.; Byun, M.W. (2003). Irradiation effects on color and functional properties of persimmon (Diospyros Kaki L. folium) leaf extract and licorice (Glycyrrhiza Uralensis Fischer) root extract during storage. Radiation Physics and Chemistry, 67, 143-148.

Kotani, M.; Matsumoto, M.; Fujita, A.; Higa, S.; Wang, W.; Suemura, M.; Kishimoto, T.; Tanaka, T. (2000). Persimmon leaf extract and astragalin inhibit development of dermatitis and IgE elevation in NC/Nga mice. Journal of Allergy and Clinical Immunology, 106, 159-166.

Kwok, B.H.L.; Hu, C.; Durance, T.; Kitts, D.D. (2004). Dehydration techniques affect phytochemical contents and free radical scavenging activities of Saskatoon berries (Amelanchier alnifolia Nutt.). Journal of Food Science, 69, S122-S126.

Larson, R.A. (1988). The antioxidants of higher plants. Phytochemistry, 27, 969-978.

Lee, J.S.; Lee, M.K.; Ha, T.Y.; Bok, S.H.; Park, H.M.; Jeong, K.S.; Woo, M.N.; Do, G.-M.; Yeo, J.-Y.; Choi, M.-S. (2006). 
Supplementation of whole persimmon leaf improves lipid profiles and suppresses body weight gain in rats fed highfat diet. Food and Chemical Toxicology, 44, 1875-1883.

Matsumoto, M.; Kotani, M.; Fujita, A.; Higa, S.; Kishimoto, T.; Suemura, M.; Tanaka, T. (2002). Oral administration of persimmonleaf extract ameliorates skin symptoms and transepidermal water loss atopic dermatitis model mice, NC/Nga. British Journal of Dermatology, 146, 221-227.

Matsuo, T.; Ito, S. (1978). The chemical structure of kaki-tannin from immature fruit of the persimmon (Diospyros kaki). Agricultural and Biological Chemistry, 42, 1637-1643.

Okos, M.R.; Narsimhan, G.; Singh, R.K.; Witnauer, A.C. (1992). Food dehydration. D.R. Heldman, D.B. Lund (Eds.), Handbook of Food Engineering, Marcel Dekker, New York (1992).

Parr, A. J.; Bolwell, G.P. (2000). Phenols in the plant and in man: The potential for possible nutritional enhancement of the diet by modifying the phenols content or profile. Journal of the Science of Food and Agriculture, 80, 985-1012.

Peter, C.; Wootton-Beard; Ryan, L. (2011). Improving public health?: The role of antioxidant-rich fruit and vegetable beverages. Food Research International, 44, 3135-3148.

Piccaglia, R.; Marotti, M.; Giovanelli, E.; Deans, S.G.; Eaglesham, E. (1993). Antibacterial and antioxidant properties of Mediterranean aromatic plants. Industrial Crops and Products, 2, 47-50.

Pinela, J.; Barros, L.; Dueñas, M.; Carvalho, A. M.; SantosBuelga, C.; Ferreira, I. C. (2012). Antioxidant activity, ascorbic acid, phenolic compounds and sugars of wild and commercial Tuberaria lignosa samples: Effects of drying and oral preparation methods. Food Chemistry, in Press, Accepted Manuscript. 
Puupponen-Pimiä, R.; Nuutila, A. M.; Aarni, M.; OksmanCaldentey, K. (2003). Comparison of antioxidant activities of onion and garlic extracts by inhibition of lipid peroxidation and radical scavenging activity. Food Chemistry, 81, 4, 485-493.

Ratti, C. (2001). Hot air and freeze-drying of high-value foods: a review. Journal of Food Engineering, 49, 4, 311-319.

Sakanaka, S.; Tachibana, Y.; Okada, Y. (2005). Preparation and antioxidant properties of extracts of Japanese persimmon leaf tea (kakinoha-cha). Food Chemistry, 89, 569-575.

Shahidi, F. (2000). Antioxidants in food and food antioxidants. Food/Nahrung, 44,158-163.

Shahidi, F.; Liyana-Pathirana, C.M.; Wall, D.S. (2006). Antioxidant activity of white and black sesame seeds and their hull fractions. Food Chemistry, 99, 478-483.

Schieber, A.; Stintzing, F.C.; Carle, R. (2001). By-products of plant food processing as a source of functional compounds - recent developments. Trends in Food Science \& Technology, 12, 11, 401-413.

Sun, L.; Zhang, J.; Lu, X.; Zhang, L.; Zhang, Y. (2011). Evaluation to the antioxidant activity of total flavonoids extract from persimmon (Diospyros kaki L.) leaves. Food and Chemical Toxicology, 49, 2689-2696.

Tanaka, T.; Higa, S.; Hirano, T.; Kotani, M.; Matsumoto, M.; Fujita, A.; Kawase, I. (2003). Flavonoids as potential antiallergic substances. Current and medicinal chemistry. Anti-Inflammatory Anti-Allergy Agents, 2, 57-65.

Volden, J.; Borge, G.; Bengtsson, G. B.; Hansen, M.; Thygesen, I. E. ; Wicklund, T. (2008). Effect of thermal treatment on glucosinolates and antioxidant-related parameters in red 
cabbage (Brassica oleracea L. ssp. capitata f. rubra). Food Chemistry, 109, 3, 595-605.

Wang, S.; Melnyka, J. P.; Tsao, R.; Marcone, M. F. (2011). How natural dietary antioxidants in fruits, vegetables and legumes promote vascular health. Food Research International, 44, 14-22.

Zhang, D.; Hamauzu, Y. (2004). Phenolics, ascorbic acid, carotenoids and antioxidant activity of broccoli and their changes during conventional and microwave cooking. Food Chemistry, 88, 4, 503-509. 
